\title{
Corrigendum: "Publicationism" and scientists' satisfaction depend on gender, career stage and the wider academic system
}

\author{
Martin Husemann, Rebecca Rogers, Sebastian Meyer and Jan Christian Habel
}

Correction to: Palgrave Communications (2017) 3 Article number: 17032 doi:10.1057/palcomms.2017.32; Published 2 May 2017; Updated 16 May 2017

The article previously lacked some information in the Acknowledgements section.

The original text read:

\section{Acknowledgements}

The authors thank all participants for filling out our online questionnaire, and for personal feedback. They further thank the mail list administrators and societies for posting our questionnaire. Specifically we would like to thank colleagues who participated in trial runs of the questionnaire and helped to improve the survey.

This has now been updated to read:

\section{Acknowledgements}

The authors thank all participants for filling out the online questionnaire, and for personal feedback. They further thank the mailing list administrators and societies for posting the questionnaire. Specifically, they would like to thank colleagues who participated in trial runs of the questionnaire and helped to improve the survey. This work was supported by the German Research Foundation (DFG) and the Technische Universität München within the funding programme 'Open Access Publishing'.

The article has been corrected online.

\section{(c) (i)}

This work is licensed under a Creative Commons Attribution 4.0 International License. The images or other third party material in this article are included in the article's Creative Commons license, unless indicated otherwise in the credit line; if the material is not included under the Creative Commons license, users will need to obtain permission from the license holder to reproduce the material. To view a copy of this license, visit http://creativecommons.org/licenses/by/4.0/

(C) The Author(s) 2017 